DOI 10.37882/2223-2982.2021.12.40

\title{
ТЕОРЕТИЧЕСКИЕ КОМПОНЕНТЫ ПРАКТИКО- ОРИЕНТИРОВАННОГО ОБУЧЕНИЯ
}

\section{THEORETICAL COMPONENTS OF PRACTICE-ORIENTED LEARNING}

\section{Edieva \\ A. Murtazaev Z. Okazova}

Summary: Integration processes at the present stage have become part of the life of modern society and the educational sphere is no exception. Purpose of the research: to consider the possibilities of using the system of practice-oriented teaching of schoolchildren in the study of disciplines of an applied orientation. Practice-oriented learning is a pedagogical process, the achievement of the goals of which is associated with the acquisition of direct practical experience. So there is a need to adjust the requirements for practice-oriented learning: the use of specific practical tasks in work; modeling a practical situation only when working in groups; activation of interdisciplinary connections. If these requirements are met, it is possible to form a practice-oriented educational environment in the education process. The implementation of practice-oriented learning is due to the use of practice-oriented learning technologies in the educational process.

Keywords: practice-oriented approach, educational process, upbringing, lesson and extracurricular activities.

\author{
Эдиева Инна Адлановна \\ Чеченский государственный педагогический \\ университет, Грозный \\ Муртазаев Аюб Мусибекович \\ Чеченский государственный педагогический \\ университет, Грозный \\ Оказова Зарина Петровна \\ Д.с.-х.н., профессор, Чеченский государственный \\ педагогический университет, Грозный \\ okazarina73@mail.ru
}

Аннотация: Процессы интеграции на современном этапе стали частью жизни современного общества, и образовательная сфера не явилась исключением. Цель исследования: рассмотреть возможности использования системы практико-ориентированного обучения школьников при изучении дисциплин прикладной направленности. Практико-ориентированное обучение представляет собой педагогический процесс, достижение целей которого связано с приобретением непосредственно опыта практической деятельности. Так возникает необходимость корректировки требований к практико-ориентированному обучению: использование конкретных практических задач в работе; моделирование практической ситуации только при работе в группах; активизация межпредметных связей. При соблюдении указанных требований есть возможность формирования практико-ориентированной образовательной среды в процессе образования. Осуществление практикоориентированного обучения идет за счет использования в учебном процессе практико-ориентированных технологий обучения.

Ключевые слова: практико-ориентированный подход, образовательный процесс, воспитание, урочная и внеурочная деятельность.

дартно мыслить, готовых к профессиональному поиску и самообразованию [2].

К сожалению, несмотря на необходимость прикладной направленности образования, количество часов, отведенных на изучение дисциплин прикладной направленности, планомерно сокращается. Итог - практико ориентированные технологии в учебном процессе используются в недостаточном объеме.

Перед образовательными учреждениями стала задача - сформировать качественно новую практико-ориентированную образовательную среду, отвечающую требованиям современного общества [7].

Нельзя не отметить сложившуюся достаточно противоречивую ситуацию в области применения практико-ориентированного обучения - происходящие в современном обществе изменения, в частности, в сфере безопасности жизнедеятельности, еще раз подтвердили ее прикладной характер. 
Все вышеизложенное обусловило выбор темы исследования.

Цель исследования: рассмотреть возможности использования системы практико-ориентированного обучения школьников при изучении дисциплин прикладной направленности.

Основным методом исследования я вился теоретический анализ имеющихся результатов и методических разработок, который позволил сделать обоснованные выводы.

\section{Результаты исследования и их обсужАение}

Первым этапом работы явилось определение предпосылок ведения практико-ориентированного обучения $[7,11]$.

В образовательной среде на современном этапе достаточное количество направлений в трактовке термина «практико-ориентированное обучение». Но актуальными признаны лишь три, где дифференциация происходит по степени охвата элементов образовательного процесса:

1. Связь практико-ориентированного обучения с формированием опыта практической работы школьников при их максимальном приближении в процессе практических работ, к среде близкой к профессиональной (Ю. Ветров, Н. Клушина).

2. Внедрение технологий, имеющих профессиональную направленность и методик моделирования элементов профессиональной деятельности (T. Дмитриенко, П. Образцов).

3. Внедрение технологий, направленных на приобретение навыков практической работы для того, чтобы эффективно решать поставленные задачи. При такой направленности имеет место четко выраженная мотивация к накоплению опыта решения практических вопросов. (Ф.Г. Ялалов).

На основе последних двух можно сформулировать следующее:

1. Практико-ориентированное обучение представляет собой педагогический процесс, в основе которого лежит решение учебных задач на основе получения практических умений и навыков, посредством моделирования конкретных профессиональных элементов [8].

2. В основу работы положены принципы диалогизма и практико-ориентированности. Именно эти направления обеспечивают воспитание у учащихся коммуникативных универсальных учебных действий (УУД): толерантное отношение к мнениям и взглядам других людей, навыки диалогического общения - познавательные УУД: навык формулировки проблемы - и регулятивные УУД: выбор и обоснование способа выхода из проблемной ситуации.

В основе реализации практико-ориентированность находятся: конкретные ситуации, возникающие на практике, причем их сложность должна соответствовать возрастным особенностям учащихся; формирование профессиональной деятельности посредством работы в малых и средних группах; применение знаний, полученных в ходе изучения других предметов учебного плана $[2,9]$.

Реализация данного принципа позволяет формировать практико-ориентированную образовательную среду.

В результате анализа работ педагогов-практиков мы пришли к следующему определению практико-ориентированной образовательной среды.

Практико-ориентированная образовательная среда представляет собой особым образом сгенерированное образовательное поле, где гармонично сочетаются и оказывают взаимное влияние друг на друга процессуальная, целевая, содержательная составляющие. В нем ведется коммуникативная, информационная, деятельностная и профессионально-ориентированная деятельность, обеспечивающая достижения учащимся конкретных результатов. Среда направлена на саморазвитие школьников, включение их во взаимодействие с другими участниками образовательного процесса. Благодаря развитию и самообразованию всех участников образовательного процесса, совершенствуется и сама практико-ориентированная среда, развитие которой носит уже направленный характер [4, 6].

Выделены 7 уровней развития рассмотренного образовательного пространства:

1. Аморфный, который отличает отсутствие целей деятельности, не сформированные коммуникации между участниками процесса.

2. Директивный, когда происходит отбор содержания деятельности, так среда приобретает направление работы.

3. Целеустановочный, его отличает наличие целей работы у участников.

4. Аксиологический, в его ходе участники ориентируются на профессиональные ценности.

5. Стратегический - субъекты образовательного процесса приобретают конкретную стратегию работы.

6. Функционирующий, на нем среда достигает оптимальных, максимально комфортных условий для 
всех участников образовательного процесса.

7. Высший, когда субъекты отличают инновации в работе.

Для организации в школе практико-ориентированной образовательной среды высокого уровня важно придерживаться основных правил: функционирование образовательного учреждения в качестве учебно-научного комплекса; направленность на практическую применяемость и востребованность универсальных учебных действий и, безусловно, использование практико-ориентированных технологий обучения [10].

Непосредственно технологии практико-ориентированного обучения ежат в основе обучения сегодня согласно Федеральному государственному образовательному стандарту. В качестве примеров практикоориентированных технологий можно привести: интерактивное обучение, критическое мышление, проектная и исследовательская работа, проблемное обучение и наконец, информационно-коммуникационные технологии.

Кроме того, достаточно эффективным можно назвать применение указанных технологий в различных сочетаниях, когда происходит формирование конкретных практических умений и навыков.

Широкое использование практико-ориентированного подхода в обучении - это прежде всего комплекс теории и практики преподавания, а также развития учащихся. Данный подход дает возможность эффективного формирования необходимых сегодня компетенций. Учащийся является ключевой фигурой образовательного процесса, и, следовательно, главной целью практикоориентированных технологий. Педагог выступает как исполнитель, которому принадлежит второстепенная роль, он консультирует и рекомендует.

Залог эффективности практико-ориентированных технологий - сформированные педагогом условия для реализации интереса и мотивации к обучению учащихся, когда образовательный процесс становится осознаваемой потребностью. Это, как правило, комплексное использование различных методов и форм обучения.

Практико-ориентированный урок предусматривает как традиционные, так и нетрадиционные формы проведения. В частности, популярностью пользуются нетрадиционные формы лекционных занятий: проблемные лекции, лекции - визуализации, лекции - беседы, лекции с разбором кейс-заданий. В ходе проблемной лекции ставится вопрос и задача, таким образом, моделируется проблемная ситуация, решение которой осуществляется в процессе рассмотрения темы, когда учащиеся во- влекаются в диалог, активизируется познавательная деятельность.

Лекция - визуализация является воплощением принципа наглядности, когда помимо слухового задействован зрительный канал получения информации, что дает возможность активизации умственной деятельности. Это мотивация познавательной активности и интереса у учащихся. Данная форма ведения занятий позволяет создать определенный тематический каркас для мышления, формирования навыков работы с информацией, основания для самообразования [4].

Самой распространенной является лекция - беседа, которая предусматривает прямой контакт педагога и учащегося. Педагог, вызывает интерес учащихся к конкретному вопросу. Лекция - дискуссия - это совместное рассмотрение участниками образовательного процесса конкретной ситуации. Это может быть видеоролик, кадр кинофильма - ее изложение краткое, максимально информативное. Педагогом задаются наводящие вопросы, которые способны направить дискуссию в необходимом направлении. Семинарские важны в процессе повторения пройденного материала, структуризации полученных знаний. Методически правильно организованное семинарское занятие обеспечивает формирование навыков межличностного общения. Формы ведение семинаров многообразны и определяются целями занятий. Важно наличие атмосферы творчества и активного обмена мнениями, так приобретается навык выслушивать и анализировать мнение товарищей. Педагог лишь резюмирует, объективно оценивая работу и активность каждого частника образовательного процесса, указывая темы, раскрытые фрагментарно [1, 3$]$.

Нетрадиционный урок - это новые возможности как для педагога, так и для учащегося:

- учащиеся развивают как творческие способности, так и личностные качества, приобретая навык объективной оценки знаний и возможности их применения на практике;

- развивается творческая самостоятельность при работе с различными источниками информации;

- формируются оптимальные условия развития мыслительной деятельности, навык формулирования кратких выводов;

- необычные формы проведения урока, а именно элементы занимательности, способствуют активизации нестандартного мышления.

В качестве примеров нетрадиционных форм организации уроков с практико-ориентированной направленностью можно привести следующие: урок-экскурсия, урок-игра, урок-проект. 
Создание образовательной среды практико-ориентированной направленности позволит организовать целостный учебный процесс, создаст условия для воспитания конкурентоспособной личности, обеспечивая профессиональному самоопределению подростков [5].

\section{Выводы}

Практико-ориентированное обучение представляет собой педагогический процесс, достижение целей которого связано с приобретением непосредственно опыта практической деятельности. Так возникает необ- ходимость корректировки требований к практико-ориентированному обучению: использование конкретных практических задач в работе; моделирование практической ситуации только при работе в группах; активизация межпредметных связей. При соблюдении указанных требований есть возможность формирования практикоориентированной образовательной среды в процессе образования. Осуществление практико-ориентированного обучения идет за счет использования в учебном процессе практико-ориентированных технологий обучения.

\section{ЛИТЕРАТУРА}

1. Ажиев А.В., Калманова Ц.А., Гадаборшева 3.И., Тотиков 3.В., Басиева А.В. Здоровьесберегающие технологии в образовательном процессе // Свидетельство о регистрации базы данных 2020621563, 27.08.2020. Заявка № 2020621462 от 21.08.2020.

2. Ажиев А.В., Оказова 3.П., Калманова Ц.А. Методы педагогических исследований // Свидетельство о регистрации базы данных 2020620376, 28.02.2020. Заявка № 2020620221 от 18.02.2020.

3. Балан И.В. Формирование конкурентоспособной личности в условиях практико-ориентированного подхода / И.В. Балан, Л.Г. Шабалина // Материалы Всероссийской научно-методической конференции «Университетский комплекс как региональный центр образования, науки и культуры». Оренбург. 2020. C. 3619-3622.

4. Гарновская И.И. Практико-ориентированный подход как инструмент междисциплинарного синтеза на основе информационных технологий / И.И. Гарновская // Материалы Международной научно-практической конференции «Экономический рост Республики Беларусь: глобализация, инновационность, устойчивость». Минск. 2017. С. 257-259.

5. Гарновская И.И. Биоэтика и информационная этика с позиций практико ориентированного подхода / И.И. Гарновская // Материалы Региональной научно-практической конференции с международным участием «Биоэтика и современные проблемы медицинской этики и деонтологии». Витебск. 2016. C. 60-63.

6. Григорьева С.В. Практико-ориентированный подход в преподавании экологической медицины на примере практических навыков / С.В. Григорьева // Материалы 74-й научной сессии сотрудников университета «Достижения фундаментальной, клинической медицины и фармации». Витебск. 2019. C. $337-338$.

7. Громова А.П. Модульно-компетентностный подход как методологическая основа практико-ориентированного обучения / А.П. Громова // Материалы Международной научно-практической конференции «Актуальные научные вопросы и современные образовательные технологии». Тамбов. 2013. C. 37-39.

8. Зигаева И.А. Практико-ориентированный подход в образовательном процессе / Зигаева И.А., Н.Н. Никулина // Материалы Международной научнопрактической конференции «Горинские чтения. Наука молодых - инновационному развитию АПК». Майский. 2019. С. 186.

9. З Зорина С.И. Практико-ориентированный подход к обучению / С.И. Зорина // Материалы Международной научно-практической конференции «Научный вклад молодых исследователей в сохранение традиций и развитие АПК». Санкт-Петербург. 2016. С. 163-165.

10. Ланина С.Ю. Урок-экскурсия как форма реализации практико-ориентированного подхода при обучении экономике в школе / С.Ю. Ланина // Вестник научного общества студентов, аспирантов и молодых ученых. 2019. № 3. С. 57-61.

11. Оказова 3.П. Пути оптимизации процесса обучения экологии / 3.П. Оказова // Балтийский гуманитарный журнал. 2018. Т. 7. № 3 (24). С. $274-276$.

(c) Эдиева Инна Адлановна, Муртазаев Аюб Мусибекович, Оказова Зарина Петровна (okazarina73@mail.ru).

Журнал «Современная наука: актуальные проблемы теории и практики» 